\title{
Preparation of Thin Films by a Bipolar Pulsed-DC Magnetron Sputtering System Using $\mathrm{Ca}_{3} \mathrm{Co}_{4} \mathrm{O}_{9}$ and $\mathrm{CaMnO}_{3}$ Targets
}

\author{
Weerasak Somkhunthot ${ }^{1}$, Nuwat Pimpabute ${ }^{1}$, Tosawat Seetawan $^{2}$ \\ ${ }^{1}$ Program of Physics and Science Center, Faculty of Science and Technology, Loei Rajabhat University, Loei, Thailand; ${ }^{2}$ Thermoelectrics \\ Research Center, Faculty of Science and Technology, Sakon Nakhon Rajabhat University, Sakon Nakhon, Thailand. \\ Email: t_seetawan@snru.ac.th
}

Received June $7^{\text {th }}, 2012$; revised July $2^{\text {nd }}, 2012$; accepted August $5^{\text {th }}, 2012$

\begin{abstract}
The thin films were deposited on the glass substrates by an asymmetric bipolar pulsed-dc magnetron sputtering system using the $\mathrm{Ca}_{3} \mathrm{Co}_{4} \mathrm{O}_{9}$ (p-type) and $\mathrm{CaMnO}_{3}$ (n-type) targets of $60 \mathrm{~mm}$ diameter and $2.5 \mathrm{~mm}$ thickness. The targets were prepared from powder precursors, which obtained by a solid state reaction. Optical emissions from plasmas during sputter depositions of films were detected using a high resolution spectrometer. Thickness of thin film was estimated by Tolansky's Fizeau fringe method and ellipsometic measurement. Crystal structures were studied from X-ray diffraction. The thermoelectric properties were assessed from Seebeck coefficient and electrical resistivity measurements at room temperature. The power factors were calculated. It was found that the optical emission spectrums showed that the $\mathrm{Ca}$, $\mathrm{Mn}, \mathrm{Co}$ and $\mathrm{O}$ atoms were sputtered from the targets onto glass substrates. As-deposited $\mathrm{Ca}-\mathrm{Co}-\mathrm{O}$ and $\mathrm{Ca}-\mathrm{Mn}-\mathrm{O}$ films thickness values were $0.435 \mu \mathrm{m}$ and $0.449 \mu \mathrm{m}$, respectively. The X-ray diffraction patterns clearly showed amorphous nature of the as-deposited films. Determining thermoelectric properties of $\mathrm{Ca}-\mathrm{Co}-\mathrm{O}$ film gave Seebeck coefficient of $0.146 \mathrm{mV} / \mathrm{K}$, electrical resistivity of $0.473 \Omega \cdot \mathrm{cm}$, and power factor of $4.531 \mu \mathrm{W} / \mathrm{m} \cdot \mathrm{K}$ at room temperature. Ca-Mn-O film baring a high resistance was not the experimental determination of thermoelectric properties.
\end{abstract}

Keywords: Thermoelectric Thin Film; $\mathrm{Ca}_{3} \mathrm{Co}_{4} \mathrm{O}_{9} ; \mathrm{CaMnO}_{3}$; Bipolar Pulsed-DC Magnetron Sputtering System

\section{Introduction}

In the past, the metal coating in form of thin films to improve the quality of material was done by electroplating process which is often also called electro-deposition. The disadvantage of electroplating was harmful to the environment. Subsequently, the vacuum depositions were developed in chemical vapor deposition (CVD) and physical vapor deposition (PVD). CVD is a technique whereby gaseous reactants can be deposited onto a substrate. However, often dangerous by-products are removed by gas flow. PVD is a clean coating technology that involves evaporation and deposition of a material. Material vaporizes are removed from a source by physical processes such as evaporation sputtering and it is transported in the form of a vapor atomic beam through a vacuum to the substrate. Magnetron sputtering is one of PVD methods, which are widely used in thin film technology. The various types of magnetron sputtering technique are direct current (DC), alternating current (AC), radio frequency (RF), and pulsed-dc [1]. Pulsed-dc magnetron sputtering is one of the latest developments of sputtering technology for thin films deposition, which has many advantages over others. Namely, it is versatile and provides the ability to deposit thin films of oxide compounds at high deposition rate and to eliminate arcing problems of poisoned targets [2]. This is interested to apply the deposition technology. It may be possible to customize the deposition conditions so that the thin films of highly preferred orientation can be grown.

In this work, the depositions of thin films have been carried out by a bipolar pulsed-dc magnetron sputtering system using the $\mathrm{Ca}_{3} \mathrm{Co}_{4} \mathrm{O}_{9}$ and $\mathrm{CaMnO}_{3}$ targets, which were made from powder precursors obtained from the solid state reaction (SSR) route. Optical emissions from plasmas during sputter deposition of thin films were measured using a high resolution spectrometer. Crystal structures of the asdeposited films were studied from X-ray diffraction (XRD). The thickness of thin films and thermoelectric properties were investigated.

\section{Experimentation}

The preparation of thin films by a pulsed-dc magnetron sputtering system is shown in Figure 1 [3]. The details of 


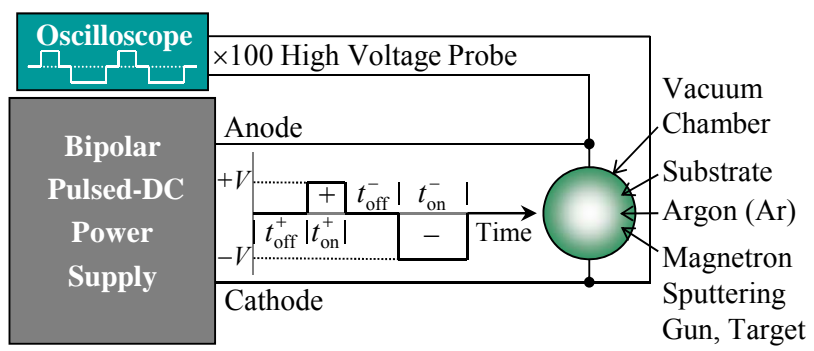

Figure 1. Experimental setup of a bipolar pulsed-dc magnetron sputtering system.

deposition conditions, plasma and characterizations, and thermoelectric properties measurements are given below.

\subsection{Deposition Conditions}

The sputtering targets were the $\mathrm{p}-\mathrm{Ca}_{3} \mathrm{Co}_{4} \mathrm{O}_{9}$ and $\mathrm{n}-\mathrm{CaMnO}_{3}$ pellets of $60 \mathrm{~mm}$ diameter, $2.5 \mathrm{~mm}$ thickness, 3.218 and $2.862 \mathrm{~g} / \mathrm{cm}^{3}$ densities, respectively. The glass slide substrates of $1.0 \mathrm{~mm}$ thick in dimension $25.0 \times 50.0 \mathrm{~mm}^{2}$ were used. The substrates were placed at a distance of $5.0 \mathrm{~cm}$ above the targets and no additional heating was applied. To generate the pulsed-dc plasma and initiate the thin film deposition, the vacuum chamber was pumped down to a base pressure of $2.00 \mathrm{~N} / \mathrm{m}^{2}$ and flushed with high purity argon (Ar 99.999\%) gas flow rate of $15.0 \pm 0.1 \mathrm{sccm}$ the total working pressures was $5.33 \mathrm{~N} / \mathrm{m}^{2}$ for sputtering from the $\mathrm{Ca}_{3} \mathrm{Co}_{4} \mathrm{O}_{9}$ and $\mathrm{CaMnO}_{3}$ targets. The pulse off time was kept constant at $14 \mu \mathrm{s}\left(t_{\text {off }}^{+}\right.$and $\left.t_{\text {off }}^{-}\right)$. The reverse positive and cathode negative pulse widths of the power supply were fixed at $10 \mu \mathrm{s}\left(t_{\mathrm{on}}^{+}\right)$and $20 \mu \mathrm{s}\left(t_{\mathrm{on}}^{-}\right)$, respectively. These values of timings give the corresponding pulse frequency of $17.24 \mathrm{kHz}$. The anode positive power was set to be the same current-voltage of $20 \mathrm{~mA}$ and $100 \mathrm{~V}$. The cathode negative current fixed at $120 \mathrm{~mA}$, the output voltage were about $260-280 \mathrm{~V}$ with deposition time of 60 minutes. Here are the optimal conditions for the deposition, which are summarized in Table 1.

\subsection{Plasma and Characterizations}

Optical emissions from plasma during sputter deposition of films were observed in the wavelength range of 360 $800 \mathrm{~nm}$ using a high resolution spectrometer (the getSpec2048 spectrometer, Sentronic $\mathrm{GmbH}$ ) as shown in Figure 2. The spectral lines were indexed to the ASD data information of National Institute of Standards and Technology [4]. Crystal structures of as-deposited films were investigated by X-ray diffractometer (PW3043 Philips X-ray diffractometer of the Netherlands) at room temperature using $\mathrm{CuK} \alpha$ radiation, $\lambda=0.15406 \mathrm{~nm}$. Each film was measured in the 2-theta angle range of $10^{\circ} \leq 2 \theta \leq 70^{\circ}$ with scanning rate of $0.02 \%$. Thin film thickness can be estimated from the optical interference using Tolansky's Fizeau fringe method which is now accepted [5]. The thickness $(t)$ of the
Table 1. Deposition conditions of thin films.

\begin{tabular}{cccc}
\hline Ar Flow Rate & Frequency & Positive Pulse & Negative Pulse \\
\hline $15.0 \pm 0.1 \mathrm{sccm}$ & $17.24 \mathrm{kHz}$ & $20 \mathrm{~mA} \mathrm{100 \textrm {V }}$ & $120 \mathrm{~mA} 260-280 \mathrm{~V}$ \\
\hline & & Window & Vacuum Chamber \\
\hline & & Detector & Substrate \\
\hline
\end{tabular}

Figure 2. Observation of optical emission from plasma during sputter deposition.

film is given by Equation (1) [6],

$$
t=\left[\frac{\Delta x}{x}\right]\left[\frac{\lambda}{2}\right]
$$

where $\Delta x$ is the displacement of fringes at step, $x$ is the distance between consecutive fringes, and $\lambda$ is the wavelength of monochromatic light. The experimental arrangement and fringe pattern is shown in Figure 3. The film thickness was measured by the Ellipsometer (Model L $115 \mathrm{~S}$ 300, Gaertner Scientific Corporation, USA) for comparison of the calculated values of thickness.

\subsection{Thermoelectric Properties Measurements}

The measurement of thermoelectric properties at room temperature in air by the Keithley instruments included the charge carrier, Seebeck coefficient, and electrical resistivity. The experimental setups can be elucidated as follows.

Firstly, the charge carrier and Seebeck coefficient were determined by hot probe method $[7,8]$ as shown in Figure 4. The hot and cold junctions between across two ends of a film were connected to the digital voltmeter (Keithley 617 Programmable electrometer). The temperatures $T_{\mathrm{H}}$ and $T_{\mathrm{C}}$ were sensed using the type $\mathrm{K}$ thermocouples, which were connected to the digital thermometers (7563 Digital thermometer, Yokogawa). The silicone thermal insulator pads were placed between junctions and thermocouples. The resistor of $10 \mathrm{~W} 5 \Omega$ was used to heat at hot junction by applying currents to a resistor placed on hot side. Seebeck coefficient $(S)$ was measured by the relation between thermoelectric voltage $(\Delta V)$ and temperature difference $(\Delta T)$. The $S$ is defined as [8]:

$$
S=\frac{\Delta V}{\Delta T}
$$

Secondly, the electrical resistivity was measured by fourpoint probe method, which can be conveniently determined by the Van der Pauw resistivity measurement technique [9] as shown in Figure 5. All contacts were made by silver paste, which showed ohmic characteristics over a wide range of currents. The current-voltage characteristics for 


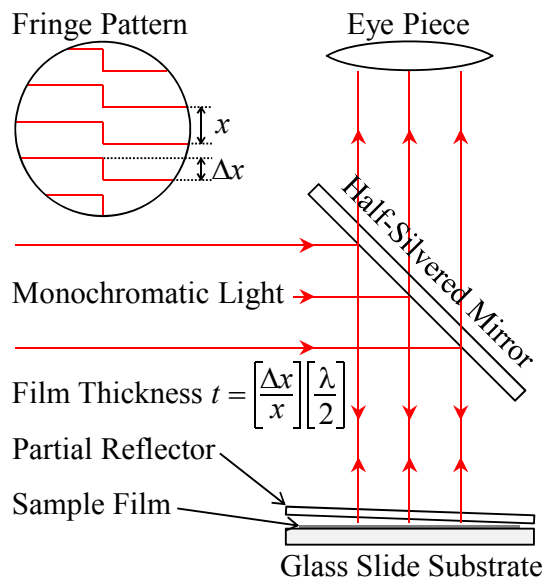

Figure 3. Experimental arrangement for Tolansky's Fizeau fringe method.

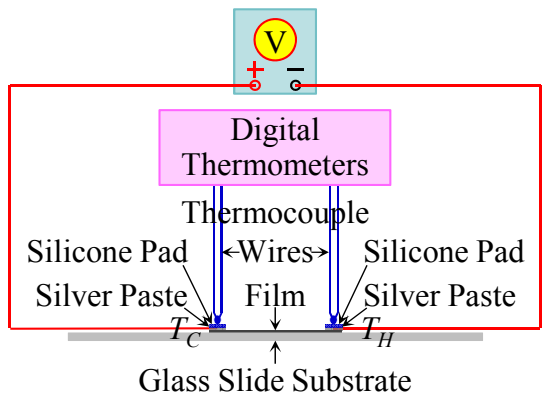

Figure 4. Side view (vertical cross section) of charge carrier and Seebeck coefficient measurement.

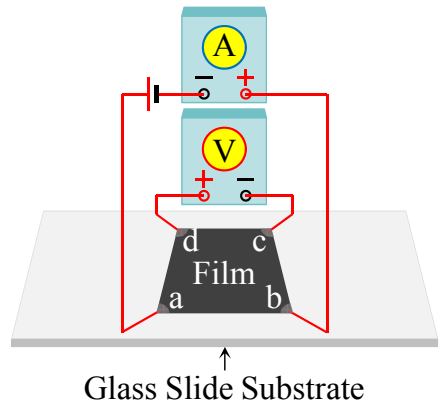

Figure 5. Three-dimensional top view of electrical resistivity measurement.

measurement of resistivity $(\rho)$ are measured. The $\rho$ can be estimated from [9]

$$
\rho=\frac{\pi t}{\ln 2}\left[\frac{R_{\mathrm{ab}, \mathrm{dc}}+R_{\mathrm{bc}, \mathrm{ad}}}{2}\right] F\left[\frac{R_{\mathrm{ab}, \mathrm{dc}}}{R_{\mathrm{bc}, \mathrm{ad}}}\right]
$$

where $t$ is the film thickness, $R_{\mathrm{ab}, \mathrm{dc}}=\Delta V_{\mathrm{dc}} / I_{\mathrm{ab}}, R_{\mathrm{bccad}}=$ $\Delta V_{\mathrm{ad}} / I_{\mathrm{bc}}$, and $F$ is correction function which can be calculated from $\left(R_{\mathrm{ab}, \mathrm{dc}}-R_{\mathrm{bc}, \mathrm{ad}}\right) /\left(R_{\mathrm{ab}, \mathrm{dc}}+R_{\mathrm{bc}, \mathrm{ad}}\right)=(F / \ln 2)$ $\arccos h[\exp (\ln 2 / F) / 2]$.

Finally, the thermoelectric efficiency can be examined from power factor $(P)$, which was calculated from the $S$ and $\rho$ in Equation (4) $[7,10]$.

\section{Results and Discussion}

The results and discussion of plasma, characterizations, and thermoelectric properties are given below.

\subsection{Plasma and Characterizations}

The cathode voltage waveforms, photographs of stable glow discharges, and optical emission spectrums of the bipolar pulsed-dc magnetron argon discharge during the sputtering of the $\mathrm{Ca}_{3} \mathrm{Co}_{4} \mathrm{O}_{9}$ and $\mathrm{CaMnO}_{3}$ targets are shown in Figure 6. These results indicated the good pulsed-dc plasma characteristics. The spectral lines were indexed to the ASD data information of NIST [4]. It was found that the emission lines of $\operatorname{Ar}(422.57,656.34,696.66,706.83$, $738.55,750.50,751.57,763.63,772.51,794.94$ and 797.25 $\mathrm{nm}), \mathrm{Ca}(370.26,393.36$ and $396.85 \mathrm{~nm}), \mathrm{Co}(361.46$ and $399.43 \mathrm{~nm})$, and $\mathrm{Mn}(361.06$ and $403.11 \mathrm{~nm})$ were prominent features. The emission line of $\mathrm{O}(777.41 \mathrm{~nm})$ was detected, but it is not intense due to the strong line of this species is not in measured range. The optical emission spectrums showed that $\mathrm{Ca}, \mathrm{Co}, \mathrm{Mn}$, and $\mathrm{O}$ atoms were sputtered from the targets. Hence, it can be expected that
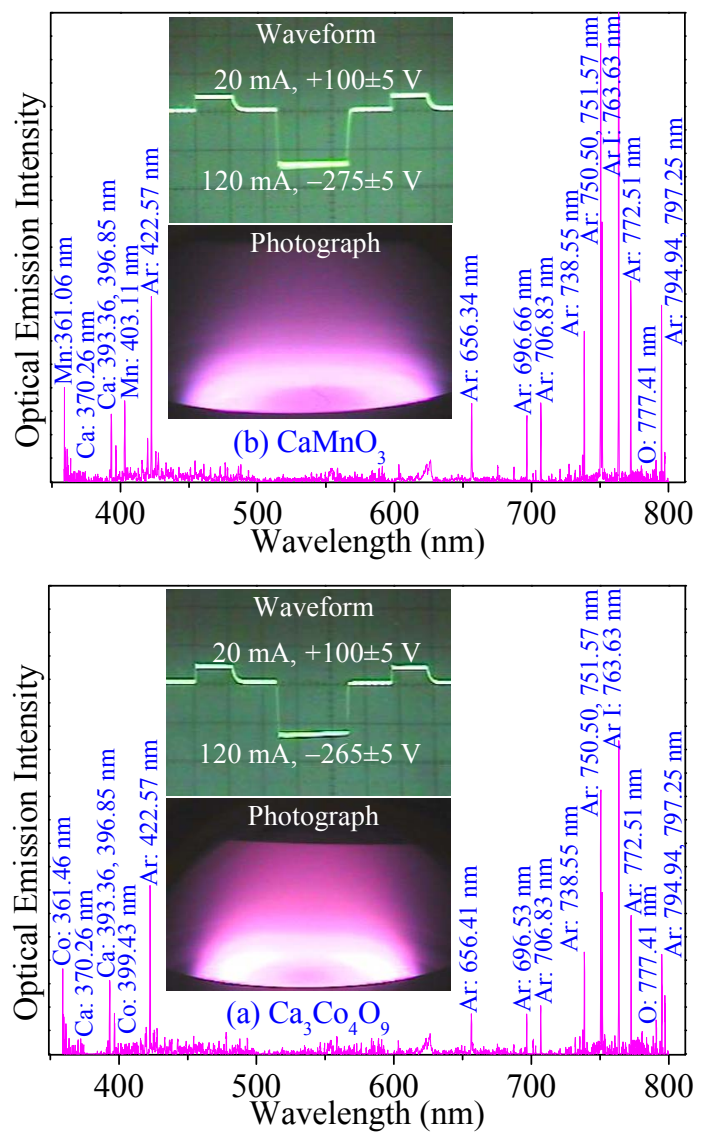

Figure 6. Waveforms, photographs, and spectral lines during the sputtering of (a) $\mathrm{Ca}_{3} \mathrm{Co}_{4} \mathrm{O}_{9}$ and (b) $\mathrm{CaMnO}_{4}$. 
the deposited films will contain these atomic species. From this point onward, the deposited films will be referred to as $\mathrm{Ca}-\mathrm{Co}-\mathrm{O}$ and $\mathrm{Ca}-\mathrm{Mn}-\mathrm{O}$ containing. The as-deposited films of $1.60 \times 1.60 \mathrm{~cm}^{2}$ and XRD patterns are shown in Figure 7. From this figure clearly indicated amorphous nature of the as-deposited films. This was expected since the substrates were not heated during the deposition process. Therefore, the kinetic energy of atomic species at the substrate surface was not enough to promote the growth of a crystal. Each film thickness was initially estimated using optical interference method (yellow sodium light, $\lambda=589.3 \mathrm{~nm}$ ) and was obtained from ellipsometic measurement (red laser light, $\lambda=632.8 \mathrm{~nm}$ ). The results are given in Table 2 . The results of measurement gave the thickness of $435.31 \mathrm{~nm}$ and $449.35 \mathrm{~nm}$ for as-deposited $\mathrm{Ca}-\mathrm{Co}-\mathrm{O}$ and $\mathrm{Ca}-\mathrm{Mn}-\mathrm{O}$ films, respectively.

\subsection{Thermoelectric Properties}

The results of investigations on thermoelectric properties of $\mathrm{Ca}-\mathrm{Co}-\mathrm{O}$ and $\mathrm{Ca}-\mathrm{Mn}-\mathrm{O}$ films such as the types of charge carrier, Seebeck coefficient, electrical resistivity, and power factor are presented and discussed.

Firstly, the types of charge carriers were determined by hot probe method (see Figure 4). The result of measurement on $\mathrm{Ca}-\mathrm{Co}-\mathrm{O}$ film, the cold junction showed higher voltage than the hot junction, indicating that the holes conduction dominated transport property (p-type). The measurement results of relation between Seebeck emf $(\Delta V)$ and temperature difference $(\Delta T)$ are shown in Figure 8. Ca$\mathrm{Co}-\mathrm{O}$ film indicated linear dependence between $\Delta V$ and

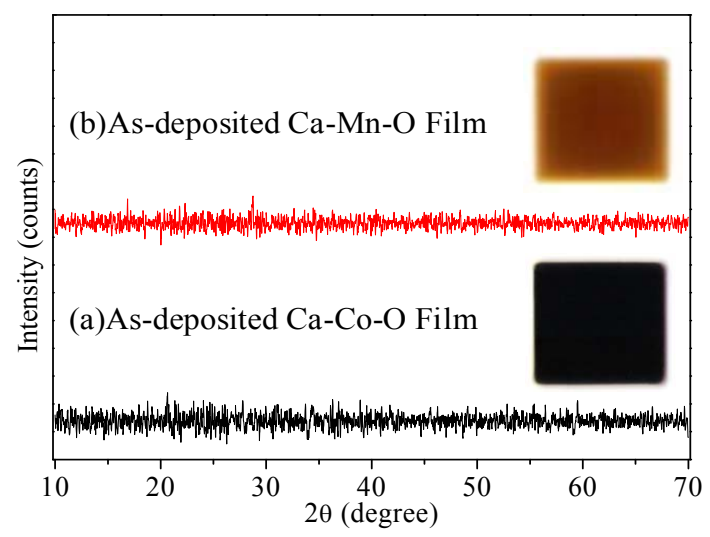

Figure 7. As-deposited Ca-Co-O and Ca-Mn-O films of $1.60 \times$ $1.60 \mathrm{~cm}^{2}$ and XRD patterns.

Table 2. Thickness of the as-deposited Ca-Co-O and Ca-Mn-O films.

\begin{tabular}{cccc}
\hline Samples & $\begin{array}{c}\text { Calculation } \\
(\mathrm{nm})\end{array}$ & $\begin{array}{c}\text { Measurement } \\
(\mathrm{nm})\end{array}$ & $\begin{array}{c}\text { Refractive } \\
\text { Index }\end{array}$ \\
\hline $\mathrm{Ca}_{3} \mathrm{Co}_{4} \mathrm{O}_{9}$ & $\sim 441.98$ & $435.31 \pm 3.37$ & $2.22 \pm 0.01$ \\
$\mathrm{CaMnO}_{3}$ & $\sim 452.50$ & $449.35 \pm 1.27$ & $2.06 \pm 0.01$ \\
\hline
\end{tabular}

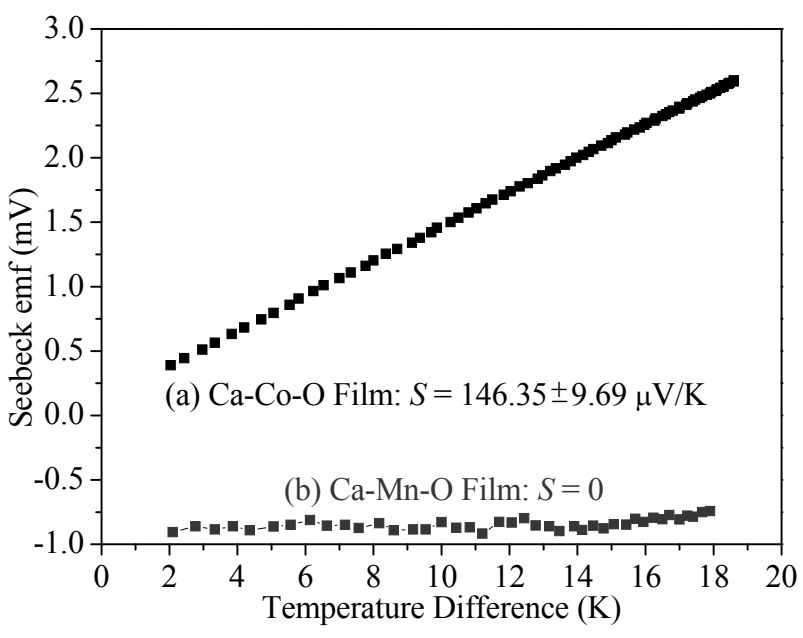

Figure 8. Seebeck emf of thin films as a function of temperature difference (a) Ca-Co-O film and (b) Ca-Mn-O film.

$\Delta T$, the $S$ of $146.35 \mu \mathrm{V} / \mathrm{K}$ is obtained. Ca-Mn-O film baring a high resistance was not the experimental determination of charge carrier and Seebeck coefficient.

Secondly, the current-voltage characteristics were obtained by the Van der Pauw four-probe measurement (see Figure 5). The experimental result of $\mathrm{Ca}-\mathrm{Co}-\mathrm{O}$ film is shown in Figure 9. The plot exhibited good ohmic $I-V$ characteristics. The $\rho$ value obtained from this $I-V$ plot, it is $0.473 \Omega \cdot \mathrm{cm}$. For the experimental measurement of $\mathrm{Ca}-$ Mn-O film could not be determined.

Finally, the power factor was calculated from $S$ and $\rho$ in Equation: $P=S^{2} / \rho$. The result of $\mathrm{Ca}-\mathrm{Co}-\mathrm{O}$ film gave value of $4.53 \mu \mathrm{W} / \mathrm{m} \cdot \mathrm{K}$.

\section{Conclusion}

The preparation of Ca-Co-O and Ca-Mn-O thin films using a bipolar pulsed-dc magnetron sputtering system were successfully deposited on glass substrates from the $\mathrm{Ca}_{3} \mathrm{Co}_{4} \mathrm{O}_{9}$ and $\mathrm{CaMnO}_{3}$ targets, respectively. The XRD patterns clearly indicated amorphous nature of the as-deposited films. Determining thermoelectric properties of $\mathrm{Ca}$ Co-O film showed the low Seebeck coefficient and high electrical resistivity, which leaded to a low power factor. Ca-Mn-O film baring a high resistance was not an experiment. The post deposition annealing and doped metals have been expected candidates for good thermoelectric properties. This will be further investigated.

\section{Acknowledgements}

This work was financially supported by the Research and Development Institute, Loei Rajabhat University (LRU). The Thermoelectric Research Center (TRC) and Sakon Nakhon Rajabhat University (SNRU) are acknowledged for the preparation of sputtering targets. Asst. Prof. Dr. Thanusit Burinprakhon, the Physics Department, Faculty of 


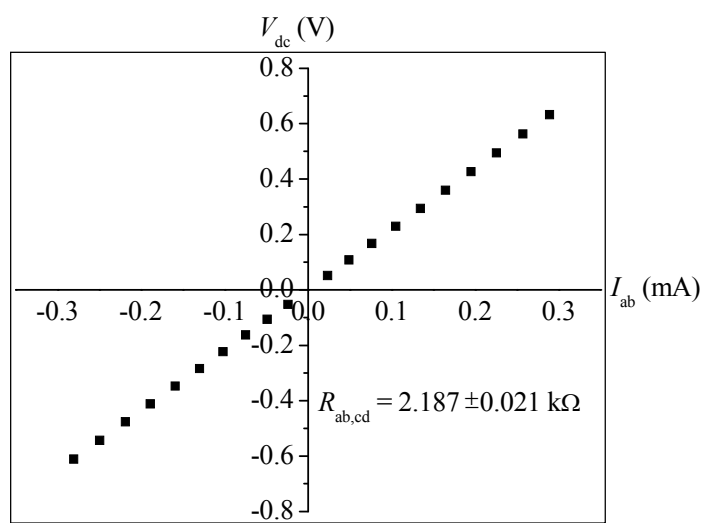

(a)

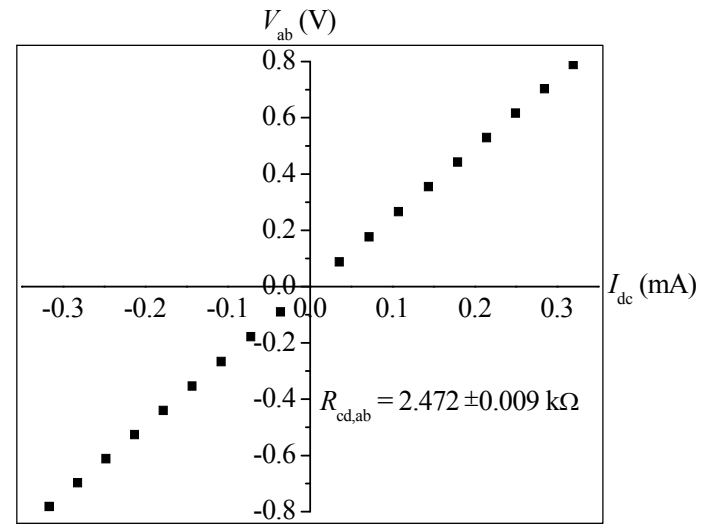

(c)

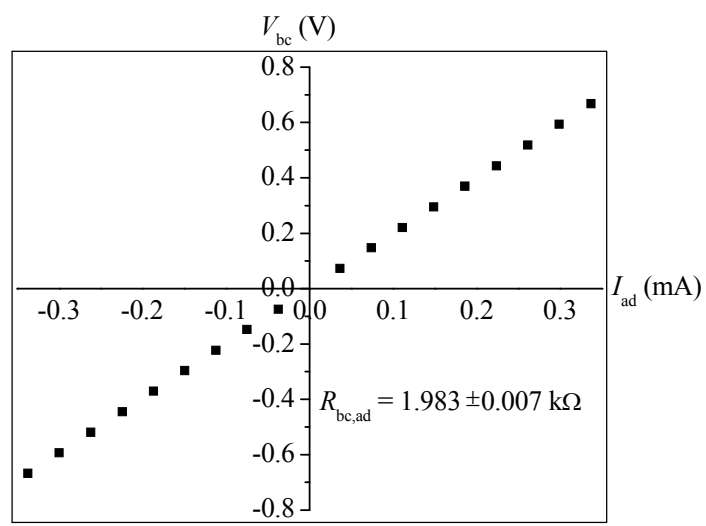

(b)

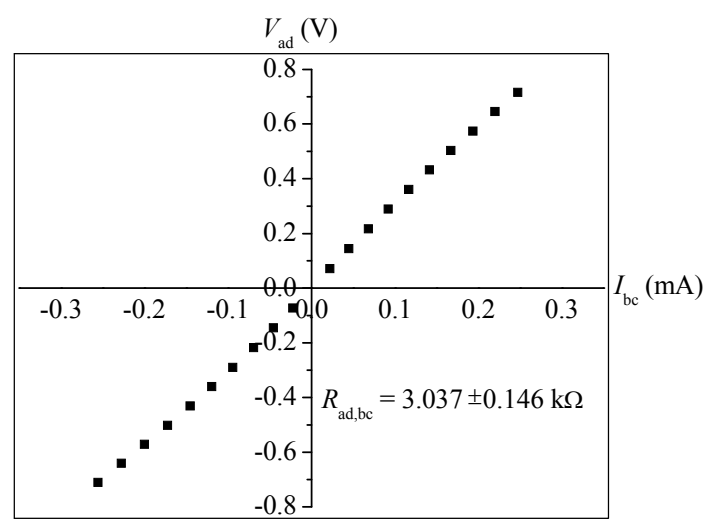

(d)

Figure 9. Plot of the current-voltage characteristics for the electrical resistivity measurement of Ca-Co-O film (a) $I_{a b}-V_{d c}$; (b) $I_{a d}-V_{b c} ;(c) I_{d c}-V_{a b}$ and (d) $I_{b c}-V_{a d}$.

Science, Khon Kaen University (KKU) is gratefully acknowledged for kind help with preparation of thin films by an asymmetric bipolar pulsed-dc magnetron sputtering system and thermoelectric characterizations.

\section{REFERENCES}

[1] D. A. Glocker, S. I. Shah and W. D. Westwood, "Handbook of Thin Film Process Technology," Institute of Physics Publication, Philadelphia, 1995.

[2] J. Sellers, "Asymmetric Bipolar Pulsed DC: The Enabling Technology for Reactive PVD," Surface and Coatings Technology, Vol. 98, No. 1-3, 1998, pp. 1245-1250. doi:10.1016/S0257-8972(97)00403-9

[3] W. Somkhunthot, T. Burinprakhon, I. Thomas, V. Amornkitbamrung and T. Seetawan, "Bipolar Pulsed-DC Power Supply for Magnetron Sputtering and Thin Films Synthesis," Elektrika: Journal of Electrical Engineering, Vol. 9, No. 2, 2007, pp. 20-26.
[4] J. Curry, "NIST Atomic Spectra Database," 2012. http://www.nist.gov/pml/data/asd.cfm

[5] S. Tolansky, "An Introduction to Interferometry," Kongmans, Green \& Co. Ltd., London, 1955.

[6] K. Jayachandran, "Electrical, Optical and Structural Studies in Bismuth, Antimony, Bismuth Oxide and Antimony Oxide Thin Films," Ph.D. Thesis, Mahatma Gandhi University, Kerala, 1997.

[7] B. V. Zeghbroeck, "Principles of Semiconductor Devices," 2011. http://ecee.colorado.edu/ bart/book/

[8] G. S. Nolas, J. Sharp and H. J. Goldsmid, "Thermoelectrics: Basic Principles and New Materials Developments," Springer-Verlag, Berling, 2001.

[9] L. J. van der Pauw, "A Method of Measuring the Resistivity and Hall Coefficient on Lamellae of Arbitrary Shape," Philips Technical Review, Vol. 20, No. 8, 1958, pp. 220-224.

[10] D. M. Rowe, "CRC Handbook of Thermoelectrics," CRC Press, Boca Raton, 1995. doi:10.1201/9781420049718 